\title{
Note on Transcriptions and Use of Tigrinya Terms
}

$\mathbf{T}$ igrinya is a Semitic language, related to Amharic (the national language of Ethiopia), Hebrew, and Arabic. It is derived from the ancient liturgical language Ge'ez. ${ }^{1}$ Its written form is made up of syllabic symbols (consonant-vowel combinations). The basic syllabary is made up of thirty-three different roots, and each root has at least seven variations. In addition, there are thirty-seven special characters.

I learned to read the Amharic and Tigrinya syllabary (the two languages use the same basic syllabary, which differs only in the way that a few symbols are pronounced) prior to beginning my research. However, most of my language learning was done through listening and speaking with Tigrayans. In the interests of accuracy and saving time, I relied on a research assistant to translate most formal interviews. However, as I became more proficient in the language, I also interviewed on my own in Tigrinya.

Throughout this book, I have included terms and some translated songs or proverbs in their English and Tigrinya written forms. In many cases, where I have been able to locate the Tigrinya spelling for a term, I have included it, since transliteration of Tigrinya terms is open to wide variation. This should help Tigrinya speakers who read this book to identify the exact term to which I refer. Unfortunately, it has not been possible to identify the Tigrinya written form for all terms. Most of my informants were illiterate, and even those who were not were not accustomed to reading and writing in Tigrinya, since that language only started to be used as an official medium of written communication and for educational purposes in Tigray Region when the Ethiopian People's Revolutionary Democratic Front came to power in I99I.

To my knowledge, there is no dictionary currently available for translation of Tigrinya to English. There are, however, several useful English to Tigrinya dictionaries. I have also benefited from Wolf Leslau's Concise Ambaric Dictionary (University of California Press, 1976), Amsalu Aklilu and G. P. Mosback's English-Ambaric Dictionary (Addis Ababa, 1973), and Yohannes Gebre Egziabher's Mezgebe-K'alat Tigrinya-Ambarinya (Ethiopian Dictionary, Tigrinya-Amharic) (Asmara, 1958-59). 

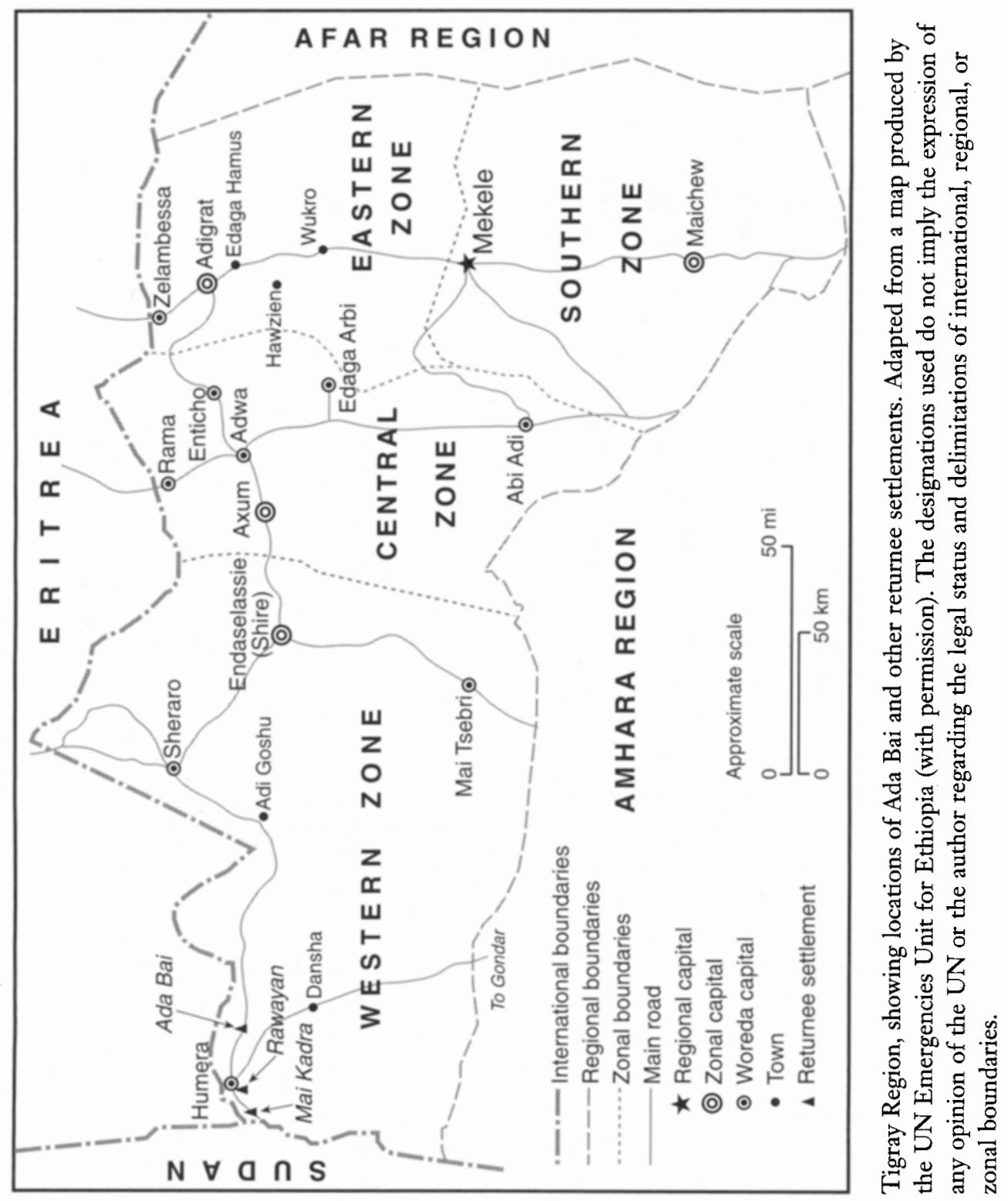
This Place Will Become Home 
